\title{
Impedance response of lead zirconate titanate thick film structures on silicon substrates for a high frequency ultrasonic transducer
}

\author{
Takashi IIJIMA, ${ }^{\dagger}$ Naoto KOCHI* and Soichiro OKAMURA* \\ National Institute of Advanced Industrial Science and Technology, AIST Tsukuba West, \\ 16-1 Onogawa, Tsukuba, Ibaraki 305-8569, Japan \\ *Department of Applied Physics, Tokyo University of Science, 6-3-1 Niijuku, Katsushika-ku, Tokyo 125-8585, Japan
}

\begin{abstract}
Micromachined ultrasonic transducers (MUTs) are attractive devices for medical imaging systems. In order to observe biological tissue images clearly, ultrasonic waves above $100 \mathrm{MHz}$ in a thickness oscillation mode are required. Therefore, the film thickness of the piezoelectric materials like lead zirconate titanate (PZT) is required less than $10 \mu \mathrm{m}$. In this study, to adapt the demand of high frequency ultrasonic, thickness mode transducers using the PZT thick film were prepared with a CSD process, a FEM simulation, and a micro fabrication process. The effects of the side length of PZT thick film structure and the Si substrate thickness on the electrical impedance properties were investigated, because the mechanical oscillation was equivalent to the electrical impedance oscillation. To reduce a series of resonance frequency like a composite resonator, a back side of the $\mathrm{Si}$ substrate was removed with deep Si etching process. The PZT thick film with Si substrate cavity structure showed sharp fundamental thickness mode resonance peak at around $168 \mathrm{MHz}$. Therefore, the fabricated device structure is applicable to the high frequency ultrasonic medical imaging system in the future.

(C)2013 The Ceramic Society of Japan. All rights reserved.
\end{abstract}

Key-words : Chemical solution deposition, PZT, Thick film, Ultrasonic transducer, MUTs, Electrical impedance

[Received April 15, 2013; Accepted June 26, 2013]

\section{Introduction}

Combination of piezoelectric film preparation techniques and the micromachining technique is interesting to develop microelectromechanical (MEMS) devices like actuators and sensors. Especially, piezoelectric micromachined ultrasonic transducers (pMUTs) are attractive devices for medical imaging systems. ${ }^{1)-6}$ ) The pMUTs are a single or an array type ultrasonic transducer device composed of the piezoelectric layer and a diaphragm structure, and the ultrasonic wave is usually oscillated with bending mode. ${ }^{7), 8)}$ The pMUTs operated at a high frequency have possibilities to enhance the spatial resolution of the medical imaging devices. For instance, transducers working in the 40 to $60 \mathrm{MHz}$ have been studied for skin, intravascular, and ophthalmic imaging. ${ }^{4)}$ Concerning about the biological tissue imaging system, a needle type ultrasonic probe using a thin fiber is proposed to obtain high resolution microscopic image in the order of $10 \mu \mathrm{m} .{ }^{9), 10)}$ In order to observe biological tissue images clearly, ultrasonic waves above $100 \mathrm{MHz}$ are required. Comparing with the piezoelectric film materials such as $\mathrm{ZnO}$ and $\mathrm{AlN},{ }^{11), 12)}$ the lead zirconate titanate (PZT) film shows high piezoelectric response. Moreover, with increasing the oscillation frequency, the diaphragm size decreases and the difficulty of the device fabrication process increases for the bending mode transducer devices. Therefore, the thickness mode oscillation is better than the bending oscillation mode for the high frequency ultrasonic transducer above $100 \mathrm{MHz}$. In the case of a thickness mode operation for the high frequency pMUTs above $100 \mathrm{MHz}$, the film thickness of the PZT is required less than $10 \mu \mathrm{m}$, because

Corresponding author: T. Iijima; E-mail: Iijima-t@aist.go.jp the ultrasonic frequency is inversely proportional to the piezoelectric film thickness. ${ }^{13), 14)}$ Various PZT thick film fabrication processes such as an aerosol, a hydrothermal, and a composite sol-gel are reported. ${ }^{15)-17)}$ We successfully prepared dense and micro-pores free PZT thick films using a chemical solution deposition (CSD) process, and the ferroelectric and piezoelectric properties prepared with our process showed almost comparable to the bulk PZT ceramics. ${ }^{18)}$ On the other hand, it is well known that the mechanical oscillation is equivalent to the electrical impedance oscillation. Therefore, the performance of the ultrasonic transducer is estimated with the electrical impedance response.

In this study, the thick PZT films, of which film thickness was $10 \mu \mathrm{m}$, were prepared with the CSD process, and the thickness mode transducer device structures on Si substrates were fabricated using a micromachining technique. The effect of the PZT thick film transducer device geometry on the electrical impedance response was examined, and the results were compared with finite element method (FEM) simulations to design an optimized device structure.

\section{Experimental procedure}

\subsection{Fabrication process of PZT thick film struc-} tures

$\mathrm{Pb}_{1.1}\left(\mathrm{Zr}_{0.53} \mathrm{Ti}_{0.47}\right) \mathrm{O}_{3}$ precursor solution was deposited on a 2inch $\mathrm{Pt} / \mathrm{Ti} / \mathrm{SiO}_{2} / \mathrm{Si}$ substrate using a chemical solution deposition (CSD) process. Thickness of the Pt/Ti bottom electrode and Si substrate were about $200 \mathrm{~nm}$ and $280 \mu \mathrm{m}$, respectively. The sequence of spin coating and pyrolysis at $500^{\circ} \mathrm{C}$ for 3 min was repeated three times, and then the precursor films were fired at $700^{\circ} \mathrm{C}$ for $5 \mathrm{~min}$ in air. This process was repeated with a computer controlled automatic coating and firing system composed of a 


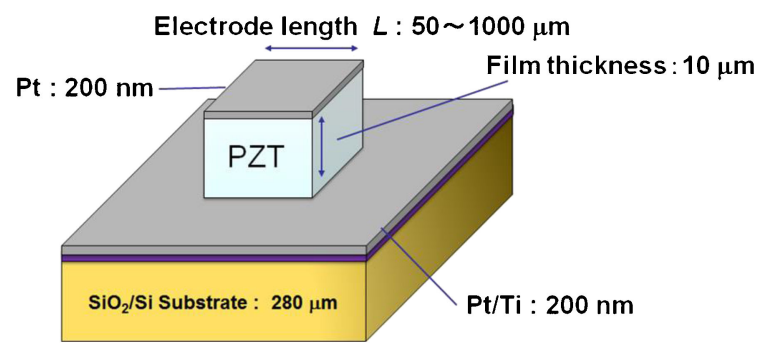

Fig. 1. Schematic illustration of the prepared PZT thick film structures.

dispenser, a spin coater, and an infrared lamp furnace to increase the PZT film thickness up to $10 \mu \mathrm{m}$. Then, a $200 \mathrm{~nm}$ Pt top electrode was sputtered, and the Pt and the PZT layer were etched by reactive ion etching (RIE) process (Plasmalab 80; Oxford Instruments) using a standard photolithography technique. Consequently, the PZT thick film structures were fabricated. Details of the preparation process of the PZT thick films were described elsewhere. ${ }^{18)}$ Figure 1 shows the schematic illustration of the prepared PZT thick film structures. The side length of the square shaped PZT film structures was varied from 50 to $1000 \mu \mathrm{m}$.

\subsection{Characterization of piezoelectric responses for PZT thick film structures}

The polarization field $(P-E)$ hysteresis curves and the piezoelectric induced longitudinal displacement curves were measured with a ferroelectric test system (FCE-1; Toyo Corporation) connected with a twin beam laser interferometer system. This system consisted of two individual laser interferometers (MLD102, MLD-301A; NEOARK). Each of the interferometers measured the displacement of the top electrode side and the bottom substrate side separately to reduce the effect of the substrate bending, and the system could measure the $P-E$ hysteresis and longitudinal displacement curve simultaneously. ${ }^{19)}$ The measurement frequency was $100 \mathrm{~Hz}$, and the amplitude of the bipolar electric fields was $100 \mathrm{kV} / \mathrm{cm}$.

An electrical impedance response were measured after a poling process at $100 \mathrm{kV} / \mathrm{cm}$, which was about four times higher than the coercive field of the prepared PZT film, for $10 \mathrm{~min}$ at room temperature. An impedance analyzer (E4991A; Agilent Technologies) was used to measure the electrical impedance of the PZT thick film structures. A high frequency prove (ACP40; Cascade Microtech, Inc.) was used to measure an impedance spectra between $1 \mathrm{MHz}$ and $1 \mathrm{GHz}$ after the open and short calibration. Because the prepared samples had a bump of topbottom electrode difference in level, the prove head was tilted to keep good contact between the prove and the samples.

On the basis of the experiment, two-dimensional FEM simulations were performed with PZFlex as a standard FEM program (Weidlinger Associates, Inc.) to compare with the characteristics of the experimental results. A two-dimensional capacitor model was composed with $\mathrm{Pt} / \mathrm{PZT} / \mathrm{Pt} / \mathrm{Si}$ layers, and the geometry of the model was comparable to the fabricated PZT structures as shown in Fig. 2. The models were divided into mesh of rectangular shaped elements. The mesh size was set to $1 / 20$ of smallest wavelength in the simulations, and 3 million elements were used at a maximum. To reduce the computation time, only a half of the model was analyzed with symmetry boundary conditions. The material parameters of the bulk PZT ( $\mathrm{Zr}: \mathrm{Ti}=$ 52:48) listed in Table $\mathbf{1}^{20}$ ) were used in the simulation, and Table 2 shows the material parameters of $\mathrm{Si}$ substrate and Pt electrode embedded in the FEM program.

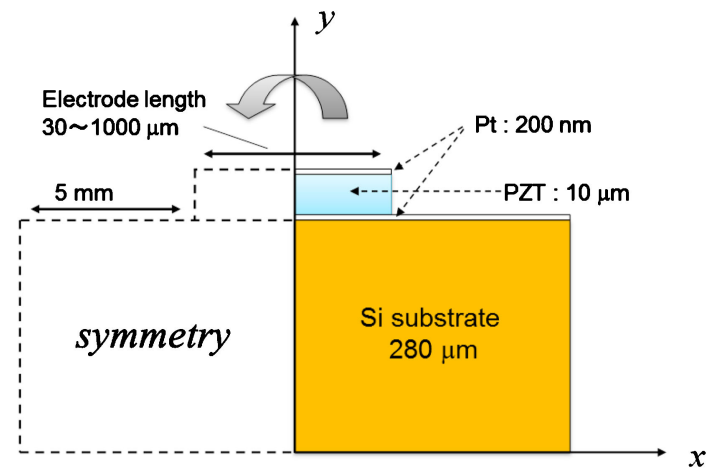

Fig. 2. Prepared two-dimensional FEM simulation model.

Table 1. Material parameters of PZT $(\mathrm{Zr}: \mathrm{Ti}=52: 48)$ used in the FEM simulation, where $\rho$ is the density, $d$ is the piezoelectric constant, $\varepsilon$ is the electric permittivity, and $s$ is the elastic compliance ${ }^{20)}$

\begin{tabular}{cccc}
\hline Parameter & \multicolumn{4}{c}{ Parameter } \\
\hline$\rho\left(10^{3} \mathrm{~kg} / \mathrm{m}^{3}\right)$ & 7.55 & $s_{11} \mathrm{E}\left(10^{-12} \mathrm{~m}^{2} / \mathrm{N}\right)$ & 13.8 \\
$d_{15}\left(10^{-12} \mathrm{~m} / \mathrm{V}\right)$ & 494 & $s_{12}{ }^{\mathrm{E}}\left(10^{-12} \mathrm{~m}^{2} / \mathrm{N}\right)$ & -4.07 \\
$d_{31}\left(10^{-12} \mathrm{~m} / \mathrm{V}\right)$ & -93.5 & $s_{13}{ }^{\mathrm{E}}\left(10^{-12} \mathrm{~m}^{2} / \mathrm{N}\right)$ & -5.80 \\
$d_{33}\left(10^{-12} \mathrm{~m} / \mathrm{V}\right)$ & 223 & $s_{33}{ }^{\mathrm{E}}\left(10^{-12} \mathrm{~m}^{2} / \mathrm{N}\right)$ & 17.1 \\
$\varepsilon_{11}{ }^{\mathrm{T}} / \varepsilon_{0}$ & 1180 & $s_{44}{ }^{\mathrm{E}}\left(10^{-12} \mathrm{~m}^{2} / \mathrm{N}\right)$ & 48.2 \\
$\varepsilon_{33}{ }^{\mathrm{T}} / \varepsilon_{0}$ & 730 & $s_{66}\left(10^{-12} \mathrm{~m}^{2} / \mathrm{N}\right)$ & 38.4 \\
\hline
\end{tabular}

Table 2. Material parameters of electrode and substrate materials used in the FEM simulation

\begin{tabular}{cccc}
\hline Material & $\begin{array}{c}\text { Density } \\
\left(10^{3} \mathrm{~kg} / \mathrm{m}^{3}\right)\end{array}$ & $\begin{array}{c}\text { Young's modulus } \\
(\mathrm{GPa})\end{array}$ & Poisson's ratio \\
\hline $\mathrm{Pt}$ & 21.4 & 16.8 & 0.32 \\
$\mathrm{Si}$ & 2.31 & 130.8 & 0.28 \\
\hline
\end{tabular}

\section{Results and discussion}

Prepared PZT thick films was (100) preferred texture orientation, and the microstructure was dense and micro-pores free with flat surface from the XRD and SEM analysis, respectively. The $P-E$ hysteresis curve showed well saturated shape, and the measured remnant polarization and coercive field at $100 \mathrm{~Hz}$, $\pm 100 \mathrm{kV} / \mathrm{cm}$ were $2 P \mathrm{r}=25.7 \mu \mathrm{C} / \mathrm{cm}^{2}$ and $2 E \mathrm{c}=42.6 \mathrm{kV} / \mathrm{cm}$, respectively. The $\operatorname{Pr}$ showed relatively low value comparing with that of the bulk PZT because the prepared PZT film showed (100) preferred texture orientation. Electrical properties of the PZT thick films prepared by our process showed good reproducibility including dielectric properties as described elsewhere. ${ }^{18)}$ The effective piezoelectric constant estimated from a decline of butterfly-shaped displacement curve was $d_{33 \text {,eff }}=142 \mathrm{pm} / \mathrm{V}$.

Figures 3(a) and 3(b) show the experimental results for the electrical impedance and phase response of the poling treated PZT film structure from $1 \mathrm{MHz}$ to $1 \mathrm{GHz}$. The side length was $30 \mu \mathrm{m}$ for Fig. 3(a) and $500 \mu \mathrm{m}$ for Fig. 3(b), respectively. Some resonant peaks were observed higher than $10 \mathrm{MHz}$, but these profiles were totally different. When the side length was $30 \mu \mathrm{m}$, two clear experimental resonant peaks (58 and $124 \mathrm{MHz}$ ) and a small resonant peak at $190 \mathrm{MHz}$ were observed in Fig. 3(a). When the side length was $500 \mu \mathrm{m}$, on the other hand, multiple resonances were observed around $150 \mathrm{MHz}$ in Fig. 3(b). Therefore, the effect of the side length on the impedance property was studied. 
Figure 4(a) shows the experimental results for the electrical impedance response of the PZT film structure changing the side length from 30 to $1000 \mu \mathrm{m}$. Figure 4(b) shows the FEM simulation results for the electrical impedance response of the PZT film structure. It can be seen that the FEM simulations were totally in good agreement with the experimental results. In experiment as shown in Fig. 4(a), with increasing the side length, intensity of the two clear resonant peaks decreased. On the other hand, intensity of the small resonant peaks just below $200 \mathrm{MHz}$ increased with increasing the side length, and the peaks showed multiple resonance when the side length was longer than $200 \mu \mathrm{m}$. Resulting from the FEM simulation in Fig. 4(b), the two clear peaks observed for a side length of 30 and $50 \mu \mathrm{m}$ were estimated lateral oscillation mode including overtone. The piezoelectric

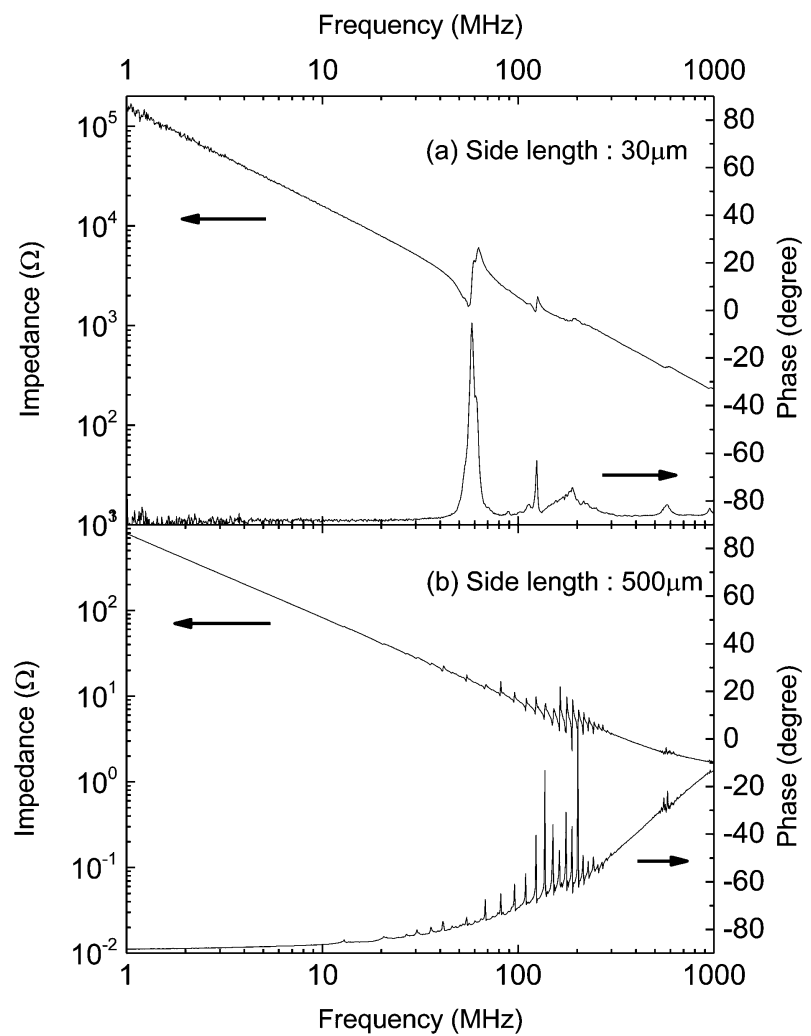

Fig. 3. Experimental results for the electrical impedance and phase response of the poling treated PZT film structure from $1 \mathrm{MHz}$ to $1 \mathrm{GHz}$. (a) side length is $50 \mu \mathrm{m}$ (b) side length is $500 \mu \mathrm{m}$. response such as the longitudinal displacement is affected by the Si substrate clumping effect, and the substrate clamping effect decreases with decreasing geometry of the PZT film structure like a diameter for a disk shape. ${ }^{21)}$ Therefore, the reason of the lateral oscillation mode observation is considered that the substrate clamping effect decreases and then a freedom of the PZT film increases with decreasing the side length of the PZT film.

On the other hand, when the side length was less than $100 \mu \mathrm{m}$, the multiple resonances with almost equal frequency interval, which was about $14 \mathrm{MHz}$, was still observed in Fig. 4(b) compared with that in Fig. 4(a). The intensity of these resonant peaks increased with increasing the side length, and these peaks mainly ranged from 40 to $250 \mathrm{MHz}$. Because the PZT film is clamped with the substrate, behavior of these series resonant peaks is caused by an oscillation of the PZT film structure including the film and the substrate like a composite resonator. ${ }^{22), 23)}$ The multiple resonances of the composite resonator are determined mainly by the acoustic properties of the materials and the thickness. The PZT film thickness corresponds to half-wavelength of the fundamental resonance, and the substrate thickness roughly corresponds to half-wavelength of the interval frequency. Additionally, the composite resonator exhibits even and odd order resonance. Therefore, the PZT thick film structure as shown in Fig. 1 seems to oscillate ultrasonic wave with a number of frequency peaks between 40 to $250 \mathrm{MHz} .^{24)-26)}$

To reduce the number of the spurious peaks, the relation between the substrate thickness and the electrical impedance response was simulated. Figure 5 shows the electrical resonance frequency dependence on the substrate thickness in the FEM simulation for the 500- $\mu \mathrm{m}$-side length structure. With decreasing the substrate thickness, the frequency interval at the resonance spread. ${ }^{26)}$ Finally, a sharp thickness mode resonance at 160 $\mathrm{MHz}$ appeared clearly for a free-standing film, because the interval frequency of the multiple resonance peaks increased with decreasing the substrate thickness. This result suggests thinner substrate is better for the thickness mode transducer devices.

On the basis of the simulation result, a backside Si substrate was removed with a deep Si etching (Bosh) process to achieve clear thickness oscillation. Since the Si etching process stopped at $\mathrm{SiO}_{2}$ layer, a layer structure at the cavity area is $\mathrm{Pt} / \mathrm{PZT} / \mathrm{Pt} / \mathrm{Ti} /$ $\mathrm{SiO}_{2}$. Figure 6 shows a schematic illustration of the prepared samples. The thickness of the PZT layer was $10 \mu \mathrm{m}$. The bottom side thickness of the PZT film was estimated about $1.2 \mu \mathrm{m}$, and Si substrate thickness was $280 \mu \mathrm{m}$. The rate between the side length of PZT film $(L)$ and that of Si substrate cavity $(X)$ was fixed to $L: X=10: 9$, because a vibration of bending mode seemed
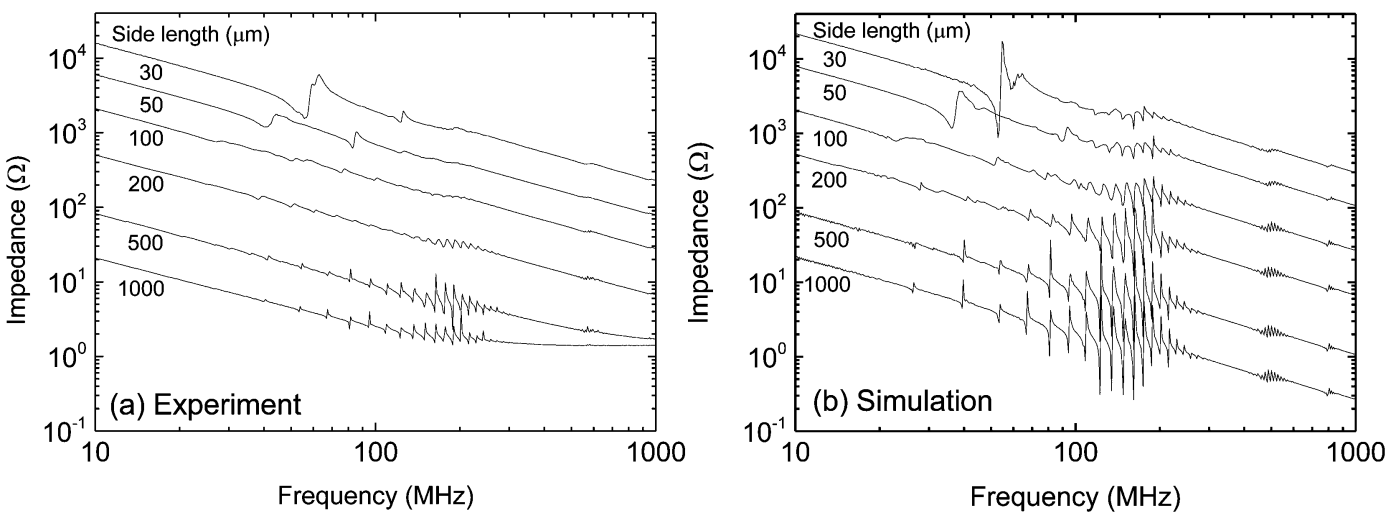

Fig. 4. (a) Experimental results for the electrical impedance response of the prepared PZT film structure. (b) FEM simulation results for the electrical impedance response of the PZT film structure. 


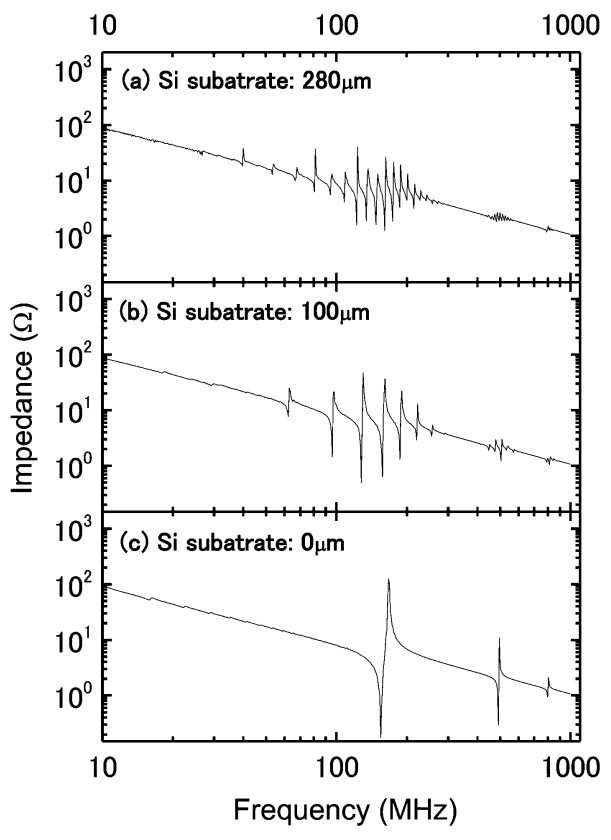

Fig. 5. Relation between the substrate thickness and the electrical resonance frequency in the FEM simulation.

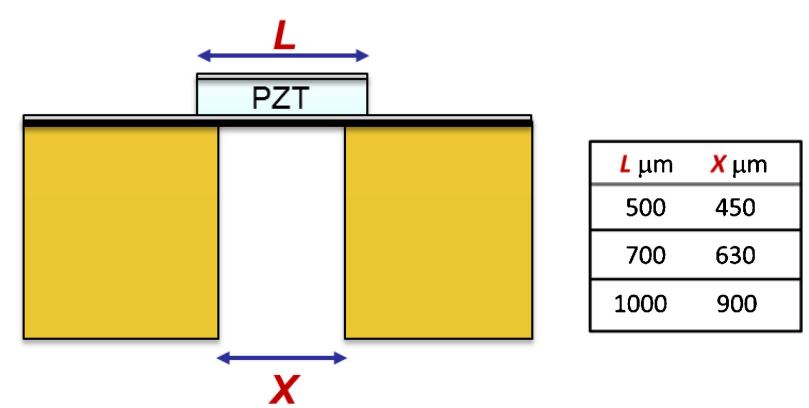

Fig. 6. Schematic illustration of the fabricated cavity structure of $\mathrm{Si}$ substrate.

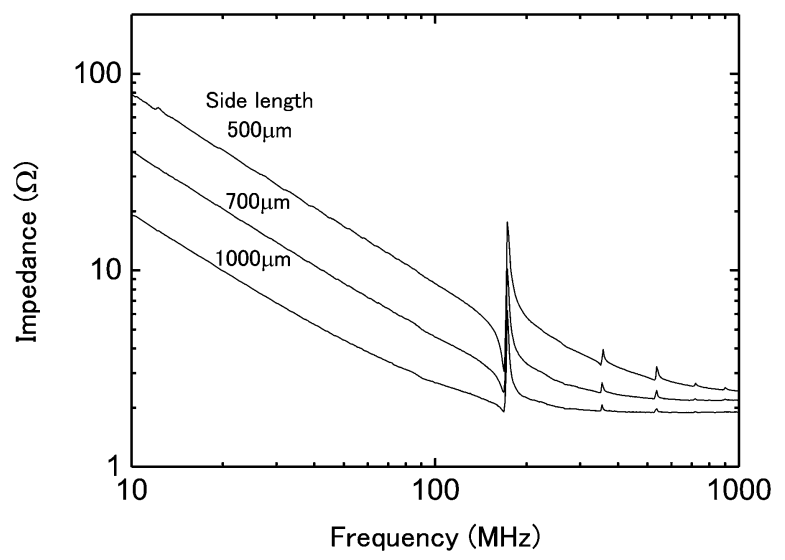

Fig. 7. Electrical impedance responses of the PZT thick film structure with Si substrate cavity.

to occur instead of a thickness mode for $L<X$. As shown in Fig. 6, the side length of the PZT film was 500, 700, and $1000 \mu \mathrm{m}$. Figure 7 shows the electrical impedance responses of the PZT thick film with Si substrate cavity structure as a function of PZT film side length. The thickness mode oscillations were observed at around $168 \mathrm{MHz}$, but the resonant frequency peaks could not be seen clearly. This is attributed to the parasitic capacitance of the measurement system. Therefore, the antiresonant frequency was determined from Fig. 7. The frequency was about $173 \mathrm{MHz}$ that was in good agreement with the simulated anti-resonant frequency, $167 \mathrm{MHz}$, as shown in Fig. 5(c), and the amount was stable when the side length $(L)$ changed from 500 to $1000 \mu \mathrm{m}$. These results suggest that the oscillation of the fundamental thickness mode can be achieved using the cavity structure. On the other hand, unexpected 2 nd resonant peaks were observed. One of the reasons for the unexpected peaks seems to be some residual Si layer of the cavity structure that means PZT thick film and back side membrane structure seem to form the composite resonator.

\section{Conclusions}

To adapt the demand of high frequency ultrasonic, thickness mode transducers using the PZT thick film were prepared with the CSD process, the FEM simulation, and the micro fabrication process. Because the mechanical oscillation was equivalent to the electrical impedance oscillation, the effects of the side length of PZT thick film structure and the Si substrate thickness on the electrical impedance properties were investigated, and the behavior of the ultrasonic oscillation higher than $100 \mathrm{MHz}$ was estimated. This means that the evaluation of the electrical impedance response can optimize the structure of the ultrasonic transducers, and the PZT thick film with Si substrate cavity structure shows sharp fundamental thickness mode resonance peak at around $168 \mathrm{MHz}$. Therefore, the fabricated device structure is applicable to the high frequency ultrasonic medical imaging system in the future.

Acknowledgments The authors would like to thank Dr. Masanao Tani and Dr. Yoshiaki Yasuda of Stanley Electric Co., Ltd. for their assistance in the deep Si etching process.

\section{References}

1) F. Akasheh, T. Myers, J. D. Fraser, S. Bose and A. Bandyopadhyay, Sens. Actuators, A, 111, 275-287 (2004).

2) P. Muralt and J. Baborowski, J. Electroceram., 12, 101-108 (2004).

3) H. Zhu, J. Miao, Z. Wang, C. Zhao and W. Zhu, Sens. Actuators, A, 123-124, 614-619 (2005).

4) F. S. Foster, C. J. pavlin, K. A. Harasiewicz, D. A. Christopher and D. H. Turnbull, Ultrasound Med. Biol., 26, 1-27 (2000).

5) Q. Zhou, S. Lau, D. Wu and K. K. Shung, Prog. Mater. Sci., 56, 139-174 (2011).

6) A. Hajati, D. Latev, D. Gardner, A. Hajati, D. Imai, M. Torrey and M. Schoeppler, Appl. Phys. Lett., 101, 253101 (2012).

7) Z. Wang, J. Miao and W. Zhu, Appl. Phys., A Mater. Sci. Process., 91, 107-117 (2008).

8) D. Akai, K. Ozaki, Y. Numata, K. Suzuki, N. Okada and M. Ishida, Jpn. J. Appl. Phys., 51, 11PA04 (2012).

9) M. Yoshizawa, T. Irie, K. Itoh and T. Moriya, Jpn. J. Appl. Phys., 47, 4176-4179 (2008).

10) T. Irie, N. Tagawa, M. Tanabe, T. Moriya, M. Yoshizawa, T. Iijima, K. Itoh, T. Yokoyama, H. Kumagai and N. Taniguchi, J. Med. Ultrasound, 38, 119-127 (2011).

11) P. M. Martin, M. S. Good, J. W. Johnston, G. J. Posakony, L. J. Bond and S. L. Crawford, Thin Solid Films, 379, 253-258 (2000).

12) G. H. Feng, C. C. Sharp, Q. F. Zhou, W. Pang, E. S. Kim and K. K. Shung, J. Micromech. Microeng., 15, 586-590 (2005).

13) Q. Q. Zhang, F. T. Djuth, Q. F. Zhou, C. H. Hu, J. H. Cha and K. K. Shung, Ultrasonics, 44, e711-e715 (2006). 
14) B. P. Zhu, D. W. Wu, Q. F. Zhou, J. Shi and K. K. Shung, Appl. Phys. Lett., 93, 012905 (2008).

15) J. Akedo, J. Am. Ceram. Soc., 89, 1831-1839 (2006).

16) B. P. Zhu, Q. F. Zhou, J. Shi, K. K. Shung, S. Irisawa and S. Takeuchi, Appl. Phys. Lett., 94, 102901 (2009).

17) Z. Wang, J. Miao and W. Zhu, J. Eur. Ceram. Soc., 27, 37593764 (2007).

18) T. Iijima, S. Osone, Y. Shimojo and H. Nagai, Int. J. Appl. Ceram. Technol., 3, 442-447 (2006).

19) Y. Kashiwagi, T. Iijima, T. Nakajima and S. Okamura, J. Ceram. Soc. Japan, 118, 640-643 (2010).

20) D. A. Berlincourt, C. Comolik and H. Jaffe, Proc. IRE, 48, 220-229 (1960).
21) T. Iijima, S. Osone, Y. Shimojo, H. Okino and T. Yamamoto, Mater. Res. Soc. Symp. Proc., 902E, 0902-T03-09 (2006).

22) C. K. Lee, S. Cochran, A. Abrar, K. J. Kirk and F. Placido, Ultrasonics, 42, 485-490 (2004).

23) Q. Chen, L. Qin and Q. M. Wang, J. Appl. Phys., 101, 084103 (2007).

24) T. R. Sliker and A. Roberts, J. Appl. Phys., 38, 2350-2358 (1967).

25) K. M. Lakin and J. S. Wang, Appl. Phys. Lett., 38, 125-127 (1981).

26) K. Nakamura, H. Sakai and H. Shimizu, Jpn. J. Appl. Phys., 20[Suppl. 20-3] 111-114 (1981). 